\title{
Conceptualization of Kindness among Adolescents of Pakistan
}

\author{
Khansa $^{1 *}$, Shazia Khalid ${ }^{2}$ and Fahad Riaz Choudhry ${ }^{3}$ \\ ${ }^{1}$ Department of Psychology, Preston University, 44000 Islamabad, Pakistan \\ ${ }^{2}$ Department of Psychology, National University of Medical Sciences, 46000 Islamabad, Pakistan \\ ${ }^{3}$ Department of Psychology, Kulliyyah of Islamic Revealed Knowledge and Human Sciences, International \\ Islamic University Malaysia, Jalan Gombak, 53100 Kuala Lumpur, Malaysia
}

\begin{abstract}
Kindness, a basic element of morality, has been observed to have a greater impact on individuals' general well-being, societal development, and integration of humanity. However, despite its phenomenal acceptance in all religions and cultures worldwide, the concept remained understudied. Therefore, qualitative research was planned to explore the phenomenon of kindness, its enabling factors, inhibiting factors, and to identify the recipients of kindness in Pakistani adolescents. An interview guide was developed in Study 1 through two Focus Group Discussions with eight girls and eight boys of 18 and 19 years to achieve the objectives. The interpretative phenomenological analysis method developed seven questions for the interview guide and then finalized through committee approach and pilot testing. In the main study, in-depth interviews were conducted on a total sample of 14 adolescents. Among which 50\% were girls between 18 and 19 years $(M=18.5, S D=$ 0.51). The data were collected from Rawalpindi and Islamabad using a convenient sampling technique and analyzed through thematic framework analysis. The results suggested that Pakistani adolescents conceptualized kindness as benefitting oneself and others with goodness and withholding harm. Religion and socialization were reported as the prime enabling factors for being kind. In addition, the availability of resources and the perception of the recipient's deservedness also determined kindness. Among the inhibitory factors, self-detaining tendencies, family and peer

ARTICLE INFO

Article history:

Received: 24 May 2021

Accepted: 12 September 2021

Published: 10 December 2021

pressure, and non-availability of resources emerged. It is hoped that the present study may enhance the understanding of kindness for future research.
\end{abstract}

DOI: https://doi.org/10.47836/pjssh.29.4.32

E-mail addresses:

khansa.psy@gmail.com (Khansa)

shazia khalid@hotmail.com (Shazia Khalid)

fahad.riaz.psy@gmail.com (Fahad Riaz Choudhry)

* Corresponding author
Keywords: Adolescents, enabling factors, in-depth interviews, inhibiting factors, kindness, recipients 


\section{INTRODUCTION}

A great number of appreciations for kindness can be found in all religions (Goodwin, 2011). Likewise, throughout most human history and nearly all cultures kindness has been regarded as a fundamental capacity of human nature. For example, Darwin (1871, as cited in DiSalvo, 2009) has referred to it as an essential element for the survival of humankind. Similarly, Peterson and Seligman (2004) have also regarded it as one of the top-ranking character strengths.

\section{Definitional Issues and Factors of Kindness}

Despite having its phenomenal use in the literature, kindness has certain significant variations in its definitions as Neff (2003) viewed kindness as self-oriented beneficial actions. In contrast, Lyubomirsky et al. (2005) described it as a behavior that benefits others. According to Otake et al. (2006), kindness encompasses recognition, motivation, and behavior.

The very notion of kindness itself is entangled with other concepts such as altruism, compassion, and prosocial behavior. Rowland (2018) elaborates the differences amongst the concepts and states that altruism is a specific exchange in which one loses something for the benefit of others, whereas kindness hardly brings loss to the giver, e.g., passing a smile. It was further asserted that kindness has both behavioral and affective components; compassion is likely an effective aspect of kindness, and prosocial behavior is more a behavioral aspect. However, these do not perfectly overlap with kindness (Rowland, 2018).
It is important to identify its dimensions and measure its degrees to explore how kindness impacts life fully. There is, in fact, just a single research study that has rigorously explored kindness. Recognizing the lack of research defining and measuring kindness, Canter et al. (2017) took a factoranalytic approach to analyze responses to a series of statements relating to kindness. They presented three different dimensions of kindness, including "benign tolerance," "empathetic responsivity," and "principled proaction." According to their conceptualization, benign tolerance involves an emotional and behavioral dimension of kindness, including courteousness, acceptance, and love of one's fellow man. Whereas "empathetic responsivity" is consideration of the specific feelings of other particular individuals, and "principled proaction" is proactive altruistic behavior towards others, driven more by cognition than emotion. Overall, these dimensions cover all three emotional, behavioral, and cognitive domains of kindness.

\section{Enabling and Inhibiting Factors of Kindness}

Several investigations using experimental methods have explored how performing (Otake et al., 2006), recalling (Exline et al., 2012), or observing (Baskerville et al., 2000) of certain kinds of acts can impact a person or others' lives. However, some studies have referred to the factors that enable an individual to be kind and control one's kindness. For example, according to Frank (2010), kindness is inherited, whereas 
Kohn (1990) and McGarry (1986) believe that observing a significant adult being kind to others makes the children kind in later life. On the other hand, some studies found that the reciprocal nature of kind acts can also serve as an enabling factor of kindness (Strenta \& Dejong, 1981). Haidt (2003) also suggested that moral elevation plays a role in boosting an individual to act out kindly. When experiencing elevation, people describe feelings inspired and uplifted and, importantly, motivated to become a better person (Haidt, 2003). In addition, people specifically report an urge of wanting to do good (Algoe \& Haidt, 2009).

Previous studies have also been highlighted numerous inhibiting factors. For example, according to Pagel (2012), people are less kind towards those they consider as out-group members. He also has described the dual moral nature of people, i.e., the capability of being extremely kind at one time and on others instantly abandoning that kindness and treating other people as sub-human (Pagel, 2012). Another inhibiting factor of kindness can be morallicensing, according to which when people are reasonably sure of their moral integrity, they have little motivation to do further good (Mazar \& Zhong, 2010; Merritt et al., 2010; Monin \& Miller, 2001; Sachdeva et al., 2009; Zhong et al., 2009 as cited in Schnall \& Roper, 2012). Moreover, according to Mischel and Shoda (1995), the situation also plays an important role in controlling kindness, i.e., some children are consistently more prosocial than others, depending on the contingencies of the situation. However, several studies indicate that with increasing age, children emphasize the intentions and constraints related to a kind act (Baldwin \& Baldwin, 1970; Leahy, 1979).

\section{Recipients of Kindness}

Another interesting aspect is that generally, people are kind to only a few people around them, whereas others are kind to humanity. It is also observed that a particular group is usually found to be more kind than the other. Following the kin-connection law of evolutionary theory, some help only their family members, some help only the person they are acquainted with, and some help everyone, including strangers. These individual differences based on the receptor of kindness are explained by little research. For example, studies confirm that people are more generous towards close ones, particularly family members, than distant others (Cialdini et al., 1997). Even the etymology began within the family; acts of kindness are commonly spread and extended to strangers when the person perceives that a kind intervention will help improve a situation or relieve a difficulty (Cleary \& Horsfall, 2016). Some people show kindness because it is the demand of their profession or social role, e.g., helping professionals (Bryan, 2015) or parents (Davey \& Eggebeen, 1998). Likewise, one's self can also be a recipient of one's kindness (Neff, 2003).

\section{Significance of Adolescents' Kindness}

The present study on adolescents' kindness hopes to bring several developments. First, 
by analyzing the Pakistani adolescents' contribution to kindness will be a productive addition to the literature. This addition of elaborating kindness, i.e., universal character strength, may also serve the inexorable rise of 'positive psychology.'

Second, adolescence, being the preparatory phase for psychosocially developed adulthood (Crosnoe \& Johnson, 2011), when studied, provides a picture of the future generation. According to 2018 estimates, adolescence covers a large portion, i.e., 21.14\% of Pakistan's population (Index Mundi, 2018).

Third, the societal need to hear about some hope in new the generation as the events of terrorism in past years have brought economic insecurities, political conflicts, emotional insecurities, and religious extremism to Pakistan's youth (Ahmed \& Khan, 2016). Moreover, past researchers have mostly focused on adolescents' problematic behaviors like substance abuse, teen violence, delinquency, suicide, eating disorders, and academic difficulties (Rich, 2003). Therefore, it is also important to highlight this youth's positive potentialities. In the current political, economic, and environmental climate, understanding kindness can play a vital role in creating positivity and hopefulness in adolescents.

\section{Aim of the Main Study}

The present research aimed to understand the phenomenon of kindness through lived experiences of people, specifically adolescents. This research-oriented around four research questions that are as follows:
1. What is the indigenous phenomenon of kindness among adolescents?

2. What are the enabling factors of kindness?

3. What are the inhibiting factors of kindness?

4. Who are the recipients of kindness?

Based on these research questions, two studies were designed.

\section{METHOD}

\section{Study 1}

Study 1 aimed to develop an interview guide, grounded in the model of Canter et al. (2017) and previous literature, and establish the tool is the face and content validity. The objectives of the present study were as follows:

1. To develop an interview guide exploring the phenomenon, enabling factors, and inhibiting factors of kindness among adolescents through their lived experiences.

2. To establish the face and content validity of the tool under expert opinion.

In qualitative research, validity refers to the extent that a method investigates what it is intended to investigate (Kvale, 1989). According to Flood and Carson,

Face validity is where a group of experts or referees assesses whether the measuring instrument measures the attribute of interest. If there is consensus among these judges (which is subjective and not necessarily repeatable), then the measuring instrument can be said to have face validity... this is also called content validity. (1993, p. 46) 
In the present study, an interview guide was pragmatically developed in 3 different phases. Four experts reviewed the developed guide on different levels to establish content validity. The experts included a female Professor in Psychology from Preston University, Islamabad (expert 1), a male Professor in Anthropology from Quaid e Azam University, Islamabad (expert 2), a male Assistant Professor in Psychology, from Fatima Jinnah Women University, Islamabad (expert 3) and a female Lecturer in Psychology, from Quaid e Azam University, Islamabad (expert 4). The details of the developmental phases of the interview guide are given below.

Phase 1. Open-ended questions were developed based on the theoretical background of the present research to achieve the objectives. The questions were reviewed and verified by experts 1 and 3 according to the research epistemology. An alternate to each question was also added to the interview guide. All the questions were based on critical realism, i.e., social phenomena are only accessible through people's representations (Bhasker, 1978, as cited in Lewis \& Ritchie, 2003). Furthermore, the present research is planned to be phenomenological, i.e., exploring a construct people use in daily life by strictly focusing on descriptions, toward a greater emphasis on interpretation being inherent in those experiences (Davidsen, 2013).

Phase 2. The standard interview guide developed in phase 1 was used in the present phase. In addition, a presentation was prepared for the Focus Group Discussion to validate the interview guide. According to Bader and Rossi (1998), pretesting a newly developed tool through Focus Group Discussion helps determine whether the vocabulary of the question is appropriate and whether the questions can stimulate discussion in an interview. It also helps identify the questions that are not easily understood (Stewart \& Shamdasani, 1990).

Sample. Sixteen key informant adolescents (8 Men and 8 Women) were selected through a convenient sampling technique. Their ages ranged from 18 to 19 years $(M=18.5, S D=$ 0.52 ) with 11 to 14 years of educational background. All the participants were residents of Rawalpindi and Islamabad. It was ensured that the selected participants were close enough to the participants selected for the main study.

Procedure. For the present Study 2, Focus Group Discussions were conducted, one for boys and the other for girls, which took 40 and 47 minutes, respectively. Formal permission was sorted from the university authorities, and the library was used for group discussions. The key informants were briefed about the purpose of the research and the time required for an interview, i.e., a minimum of 40 minutes. Verbal informed consent was given in which the participants were assured that in the research, their identifiers would not be disclosed, and their participation/withdrawal would be voluntary. 
Data Collection. The data was collected through Focus Group Discussion. The participants were shown a single item at a time through a PowerPoint presentation on a laptop. Moreover, they were asked to give an opinion about each item, i.e., to report what the question is inquiring about or what it means to them (alternate question).

Data Analysis. Two experts analyzed the data. The researcher discussed the collected data in a one-to-one session with the experts. Each item and opinion of the participants were thoroughly reviewed and amended after the experts' consensus, i.e., Expert 2 and Expert 4.

Results. The questions were modified, and the final version of the guide is shown in Table 1.
Items 1.1 and 1.2 are the alternate forms of a question used to make questions more comprehendible to the targeted population and collect more information in responses.

Phase III. This phase focused on pilot testing the developed interview guide to be used in the main study. In the pilot study, an interview was conducted with a 19-year-old male with having an educational background of 14 years. First, verbal informed consent was given after briefing about the research purpose. Then the recording of the 57 minutes long was sent to Expert 3 for review. As the participant's responses fulfilled the research objectives, the interview guide was finally approved to be used in study II.

Table 1

Semi-structured interview questions guide

\begin{tabular}{cl}
\hline No & \\
\hline 1.1 & Qhat is kindness, in your opinion? Narrate a story from your daily life. \\
1.2 & Tell us a story from your personal life in which kindness was practiced. \\
2.1 & How do you think kindness can be practiced through thoughts? Demonstrate it through an \\
& incidence of your life. \\
2.2 & Tell us a story of your life in which you have practiced kindness through thoughts? \\
3.1 & How do you think kindness can be practiced through emotions? Give an example of an incidence \\
& from your life. \\
3.2 & When do you feel kind? Relate it to any incidence of your life. \\
4.1 & In your opinion, how can kind acts be performed? Tell us an example of your life experience \\
4.2 & Telated to it. \\
5.1 & According to you what, makes a person kind? Refer to a story. \\
5.2 & In your opinion, what made you kind? Tell us a story from your life related to it. \\
6.1 & What are the factors that stop you from showing kindness? Refer to a story. \\
6.2 & When and why do you stop being kind? Relate it to any incidence of your life. \\
7.1 & Who are the recipients of your kindness in daily life? Relate it to previously stated stories. \\
7.2 & To whom can you be kind in daily life? Share your lived experience with it. \\
\hline
\end{tabular}




\section{Study 2}

The purpose of the second study was to explore the phenomenon of kindness, its enabling factors, inhibiting factors, and the recipients of kindness by using the interview guide developed in Study 1.

Population and Sample. A homogenous sample of adolescents $(\mathrm{N}=14)$, particularly of age 18 and 19 years $(M=18.5, S D=0.51)$, were selected. Four participants were recruited from Quaid-e-Azam University, five from Comsats University, and five from Bahria University Islamabad. Only the participants who were residents of Rawalpindi and Islamabad were recruited through a convenient sampling technique.

Along with it, two qualitative research experts were also recruited to review the emerging categories and themes, as suggested by Lewis and Ritchie (2003).

\section{Procedure and Ethical Considerations}

The committee gave ethical approval under the ethics approval referral number PSY-1493-116-012018. A notice was circulated in the bachelors' classes of Quaid e Azam University, Comsats University and Bahria University of Islamabad. This notice included information about research topic, nature of data collection and time required for one interview. After the participants' confirmation for voluntary participation, they were contacted to ensure the interview on a particular date and place, preferring their comfort and availability as suggested by Jacob and Ferguson (2012).
Before beginning the interview, a good rapport was first established with the participants to facilitate better responses (Jacob \& Ferguson, 2012). After the introductory session, verbal informed consent was given by the participants. On average, each interview lasted for approximately 50 minutes. The interviews followed the semi-structured interview guide that was developed in Study 1. All interviews were recorded, and 114,484 words were transcribed verbatim. The identifying information was removed or altered to keep confidentiality.

Data Analysis. The data were analyzed using a thematic framework analysis within a broadly critical realist context of phenomenology. To achieve this, 'the six-phase approach of Braun and Clarke's (2006) was followed. That includes (i) familiarization with data, (ii) generating initial codes, (iii) searching for themes, (iv) reviewing themes, (v) defining and naming themes, and (vi) producing the report.

The kappa test was used, which is a non-parametrical test to compute the interrater reliability of themes. At first, the data was analyzed by an expert for coherence and replicability of the themes. Then, after consensus with the coding of the researcher, a thematic map was provided to two judges. Finally, the level of agreement with the researcher for the developed themes was calculated for both judges in the form of kappa value. 


\section{RESULTS}

The present study was conducted to investigate the perception of kindness among Pakistan adolescents. For which the study's objectives were to explore the indigenous phenomenon of Kindness, investigate the enabling factors of Kindness, examine the inhibiting factors of Kindness, and explore the receptors of kindness. The data was collected through in-depth interviews using an interview guide developed through the phenomenological research method. Demographic characteristics of participants for the main study are presented in Table 2 .

The level of agreements between two analysts for each theme of kindness, its enabling and inhibitory factors, and recipients is shown in Table 3 . The correlation for each theme is positively significant, as shown in the table.

The collected data was analyzed through Thematic Framework Analysis. The analysis found 32 categories for the phenomenon of kindness that were grouped into three domains. The findings for the phenomenon of kindness are shown in Table 4.

Overall, the results showed three domains for the phenomenon of kindness, i.e., behavioral, emotional, and cognitive kindness, as shown in Table 4. Each domain of kindness has themes of benefitting with goodness and withholding harm. Overall, withholding harm covers a large portion of the phenomenon of kindness, i.e., 11 out of 32 categories.

The behavioral component of kindness covers $50 \%$ of the 32 categories. It generally

Table 2

Demographic characteristics of Adolescents $(\mathrm{N}=14)$

\begin{tabular}{cccccccc}
\hline No & Age & Gender & Residence & No & Age & Gender & Residence \\
\hline 1 & 19 & Male & Islamabad & 8 & 18 & Male & Islamabad \\
2 & 18 & Female & Islamabad & 9 & 19 & Male & Islamabad \\
3 & 18 & Female & Rawalpindi & 10 & 18 & Female & Rawalpindi \\
4 & 18 & Female & Islamabad & 11 & 19 & Male & Islamabad \\
5 & 19 & Female & Rawalpindi & 12 & 19 & Male & Islamabad \\
6 & 18 & Female & Rawalpindi & 13 & 19 & Male & Islamabad \\
7 & 19 & Female & Rawalpindi & 14 & 19 & Male & Islamabad \\
\hline
\end{tabular}

Note. The educational duration of each participant was 13-14 years

Table 3

The level of agreement among judges in coding the themes for the phenomenon of kindness, its enabling and inhibitory factors, and recipients $(N=14)$

\begin{tabular}{lccc}
\hline & Judge 1 & Judge 2 & Researcher \\
\hline Judge 1 & - & $.93 * *$ & $.92 * *$ \\
Judge 2 & & - & $.89 *$ \\
Researcher & & & - \\
\hline
\end{tabular}

${ }^{*} p<.05,{ }^{*} p<.01$ 
Table 4

Thematic framework analysis of the phenomenon of kindness among adolescents of Pakistan $(N=14)$

\begin{tabular}{llll}
\hline Category & Themes & Domain & Description \\
\hline - Using resources to fulfill one's own/ & Overtly benefitting self/ & Behavioral & Overtly benefitting \\
others' need & others with goodness & Kindness & with goodness or \\
- (personal, financial, human) & using tangibles & & withholding harm \\
- Taking care of people, plants, and animals & & & through behavior.
\end{tabular}

- Sharing personals \& giving gifts

- Verbal effort \& Auditory attention to make others feel better

Overtly benefitting self/

others with goodness

- Being available to soothe others

using non-tangibles

- Courteousness/ displaying good manners

- Spending time with self, people, plants, and animals

- Sharing beneficial information

- Cooperating with others in their tasks

- Asking for help: involving others in personal task

- Removing harmful objects from a pathway

- Providing shelter to refugees

- Giving a smile while controlling anger/ distress

- Opposing bullying/ protective of less powerful

- Making an effort to resolve/avoid conflict

- Stopping people from harming self/others

- Feeling others' feelings/Empathic feelings Covertly benefitting

- Being humble

self/others with

Emotional Covertly benefitting

- Showing gratitude

emotional goodness

Kindness with goodness or

- Staying trustworthy

- Giving unconditional love \& care

- Tolerance/ controlling aggression

- Avoiding gossips about others

Overtly benefitting self/ others by withholding harm using tangibles

Overtly benefitting self/ others by withholding harm using nontangibles withholding harm through emotions.

Covertly benefitting self/others by withholding emotional harm

- Positive thoughts

- Understanding others view/ Empathic understanding

Covertly benefitting

Cognitive Covertly benefitting

- Accepting one's fault

- Reactive and proactive concern

- Planning ways to make others feel good

- Being justly decisive

- Forgiving

- Refraining from believing/sharing dispute-causing/distressing information

- Praying for wrongdoers self/others with

cognitive goodness

Kindness withholding harm through cognition.
Covertly benefitting

self/others by withholding harm cognitively 
entails all the forms of kindness that are overt and exhibited through any form of observable behavior. The present study has found behavioral kindness in four different themes, i.e., being kind (i) with goodness using tangibles, (ii) with goodness using non-tangible, (iii) by withholding harm using tangibles, and (iv) by withholding harm using non-tangibles. The tangible categories include benefitting behaviors concerned with adding or removing any concrete object, i.e., money, food, gifts. In contrast, non-tangibles include the benefitting services or behaviors such as listening or cooperation as Table 4 shows, in behavioral kindness the benefitting with goodness using tangibles entail fulfilling personal (giving a discount on personal services, helping other to get a job), financial (monetary assistance), or human (giving physical support in carrying luggage) need using relevant resources. It also involves taking care of people, plants, and animals (especially when they are sick), sharing personal possessions with others, or giving gifts. On the other hand, withholding harm behaviorally to benefit others while using tangibles includes removing harmful objects from pathways and providing shelter to refugees. Whereas using nontangibles include passing smiles while controlling aggression, being protective of less powerful, trying to resolve/avoid conflict, and stopping people from harming themselves/others.

The emotional component of kindness covers 7 out of 32 categories. It includes the forms of kindness expressed through emotions for the benefit of the recipient of kindness. As shown in Table 4, it has been divided into two categories, i.e., being kind (i) with emotional goodness and (ii) withholding harm emotionally. Emotional goodness benefits contain empathic feelings, unconditional love and care, humility, gratitude, and trustworthiness. While withholding harm from an emotional perspective, kindness can be tolerance/ controlling negative emotions towards others and avoiding gossiping about others that may make them feel bad and harm their emotional health.

Table 4 shows the third domain, i.e., a cognitive form of kindness covering 9 out of 32 categories. It comprises the covert kindness that lies in cognitive processes for the benefit of the recipient of kindness. It also has been divided into two categories, i.e., being kind (i) with cognitive goodness and (ii) withholding harm cognitively. As reported by the present study participants, cognitive goodness can benefit from positive thoughts, empathic understandings, accepting one's fault, reactive and proactive concern, planning ways to make others feel good, and being just indecisive. In addition, the cognitive perspective includes forgiving, refraining from believing/sharing disputecausing/distressing information, and praying for those who have harmed you.

The findings for the enabling, inhibiting factors of kindness and recipients of kindness are given in Table 5 .

The enabling factors for kindness can be categorized into two, i.e., benefactor-related and recipient-related factors, as shown in 
Table 5

Thematic analyses for enabling factors, inhibiting factors, and recipients of kindness among adolescents of Pakistan $(N=14)$

\begin{tabular}{lll}
\hline Category & Themes & Objective \\
\hline Intrinsic & Benefactor-Related Factors & Enabling Factors \\
Nature & & \\
Nurture & & \\
Religious Orientation & & \\
Health & & \\
Optimism & & \\
Personal sufferings & Recipient-Related Factors & \\
Positive emotional state & & \\
Extrinsic & & \\
Personal Resources & & \\
Financial Resources & & \\
Human Resources & & \\
Deservedness & & \\
Profitability & & \\
Intrinsic & & \\
Personal Characteristics (comfort, loss or self- & & \\
obsession) & & \\
Extrinsic & & \\
Restriction by Significant others & & \\
Situational Constraints & & \\
Non-deservedness & & \\
Non-profitability & & \\
\hline Self & & \\
Other People & & \\
Plants and Animals & & \\
\hline & & \\
\hline
\end{tabular}

Table 5. The benefactor-related factors are further divided into two, i.e., intrinsic and extrinsic factors. The intrinsic factors contain religious orientation, i.e., people become more aware of religion, practice religion, and strongly hold a belief in prospective reciprocity of actions by divine power. Other intrinsic factors related to the benefactor are nature (innate good nature of humans and kind parental affiliation of a child), good health in some cases, optimism, and personal distress (that one has experienced personally but wants others to be protected from the harm of it). For example, an individual who was not treated kindly in a specific situation knows its real damage, so he/she will show kindness towards others in the same situation. The extrinsic factors of the benefactor are the availability of the resources, whether its workforce, financial, or any other that may fulfill the need of the recipient. On the other hand, the recipientrelated factors that may cause a person to show kindness are deservedness and the profitability of the recipient. Thus, any benefactor will be kind towards a person who is more deserving of the particular aspect of kindness, whether behavioral, emotional, or cognitive. Moreover, the present study also found that the benefactors 
of kindness are more focused on the benefit of the benefactor, i.e., a child will not be given something that may harm him/her even though he/she needs it, and the parents have resources to get it for him/her.

As shown in Table 5, the inhibiting factors are also divided into two categories, i.e., benefactor-related and recipient-related factors. The benefactor-related factors are further divided into two: one is intrinsic factors that contain personal comfort, self-obsession (an individual who is too focused on his/her personal need would pay less attention to others in need), and two, a personal loss that may stop a person from being kind. However, another factor is extrinsic that contains restrictions imposed by a significant person or situation. Along with these factors, the contraries of enabling factors can also be regarded as inhibiting factors such as not being religion-oriented, bad health, lack of parental affiliation. Finally, the recipient-related inhibiting factors are the opposites of enabling factors, i.e., non-deservedness and non-profitability of the recipient.

The present study also found the recipients of kindness, as shown in Table 5. The identified recipients in the data were self, plants, and animals (reported by few) and other people (reported by most) that included friends, family, less fortunate people, those who have harmed the benefactors particularly, and strangers.

\section{DISCUSSION}

The major contribution of the present study was to present an indigenous conceptualization of kindness among adolescents in Pakistan. According to Rich (2003), adolescence is a remarkable period of development that serves as a gateway to future adulthood. Therefore, the perception of adolescents on kindness was crucial to be studied to understand the future practice. According to Allport (1937), kindness is a central trait found in every person to a varying degree. The present study also found that some participants emphasize one of the perspectives over others. However, in general, all three aspects, i.e., behavioral, emotional, and cognitive kindnesses, are present in every individual.

The findings suggest that Pakistani adolescents perceive kindness as benefitting from goodness and withholding harm through behavior, emotion, and cognition. Despite the aspects present in daily life, the emotional and cognitive kindnesses are not paid much attention as most of the participants have focused on behavioral practices when asked about kindness in general, whereas emotional and cognitive practices of kindness were discussed upon specific inquisition of kind gestures/emotions or thoughts respectively. Moreover, a similar was found in literature, as more than half of the reviewed literature has focused on the behavioral component of kindness, few on emotional and particularly for cognitive kindness, Comunian (1998) has argued that it has not been reported in the literature.

Also, withholding harm is a new addition to the literature as the benefitting with goodness part has been latently supported by all the literature reviewed 
above and explicitly by some (Peterson \& Seligman, 2004; Pollock, 2011). In contrast, withholding harm is a new finding of the present research, although it covers a large portion of the phenomenon of kindness. Moreover, present study participants have reported withholding harm in daily life, at least in one of the perspectives of kindness. Thus, the withholding harm aspect of kindness is inevitable yet overlooked by the previous studies.

While elaborating on the three domains of kindness, the present study found that some participants may emphasize one of the domains over others. However, in general, all three, i.e., behavioral, emotional, and cognitive kindnesses, are experienced by everyone in everyday life. The behavioral domain of kindness covers overtly benefitting with goodness or withholding harm through behavior. These categories can be generally linked back to the definition given by Peterson and Seligman (2004) of doing favors and good deeds for others, yet the self, plants, and animals as recipients of kindness were overlooked. Moreover, Canter et al. (2017) and Pollock (2011) also have specifically discussed courteousness as an essential component of kindness. Emotional kindness can be termed as covertly benefitting through emotions either with goodness or by withholding harm. Some factors like empathic feeling and care have been referred to as kindness in previous studies (Binfet \& Gaertner, 2015; Peterson \& Seligman, 2004) and gratitude (Otake et al., 2006). At the same time, the present study results have recently highlighted humility and being trustworthy for other people as a form of kindness.

Moreover, the cognitive components of kindness must orient around covertly benefitting with goodness or withholding harm using cognition. Although cognitive kindness was overlooked by literature (Comunian, 1998), some of the research has referred to 'concern about welfare of other people' as kindness (Canter et al., 2017; Peterson \& Seligman, 2004).

The enabling factors of kindness can be benefactor-related, i.e., religion (religious orientation, teachings, and influential religious figures) and dispositional (empathy, optimism, mood states). Some other intrinsic factors highlighted by the present study include parental affiliation of a child. It also has been supported by literature that a child learns benefitting others from his/her parents (Kohn, 1990; McGarry, 1986), and the more he/she affiliates with a kind parent, the more he/she exhibits it (Rutherford \& Mussen, 1968). The enabling factors can also be recipient-related, i.e., perception about the recipient's deservedness and the profitability of kindness for the recipient.

Likewise, the inhibitory factors related to a benefactor can be extrinsic (i.e., constraints by significant others or situation) or intrinsic including personal limitations such as bad health and self-obsession. Some of these factors can be grounded in previous literature, such as Phillips and Taylor (2009), who termed self-serving aspiration as the reason for not being kind to others. However, another factor is extrinsic that contains restrictions from a 
significant person or situation. According to some research, the benefactor often stops being kind due to the constraints, either situational or personal (Kelley, 1967 as cited in Leahy, 1979). Along with these factors, the contraries of enabling factors can also be regarded as inhibiting factors such as not being religion-oriented, bad health, lack of parental affiliation. In comparison, the recipient-related inhibiting factors include non-deservedness and non-profitability to the recipient.

The present study also found the recipients of kindness, as shown in Table 5. As most of the previous literature has termed kindness as other-oriented except few, like Neff (2003), who has introduced self-kindness, it was necessary to understand the perception of Pakistani adolescents. The recipients of kindness in the present study have been expanded from self to plants, animals, and other people, including those who have harmed the benefactors, particularly and strangers too.

\section{CONCLUSION}

The findings can be concluded in a statement that kindness is benefitting with goodness and withholding harm behaviorally, emotionally, and cognitively. The behavioral component of kindness is overtly expressed through behavior, whereas emotional and cognitive kindness is covert benefitting through emotions and cognition. The enabling factors of kindness can be benefactorrelated, i.e., religion (religious orientation, teachings, and influential religious figures) and dispositional (empathy, optimism, mood states). Alternatively, it can also be recipient-related, i.e., perception about the deservedness of recipient and profitability of kindness for the recipient. Likewise, the explored inhibitory factors related to the benefactor can be extrinsic (i.e., constraints by significant others or situation) or intrinsic, including personal limitations such as bad health and self-obsession. At the same time, the recipient-related inhibiting factors can be non-deservedness and non-profitability to the recipient. The benefactor of kindness may be kind to oneself, other people, plants, and animals. Therefore, it is dependent on the nature of enabling and inhibiting factors.

\section{Limitations}

The sample size for the present study was very homogenous and small, limiting the phenomenon's exhaustiveness. On the other hand, the availability of the participants and the arrangement of space according to the participant's preference were laborious. Moreover, this research did not look for individual differences based on demographics among participants.

\section{Recommendation}

The findings of this study suggest several fruitful avenues for future research on the exploration of individual differences in kindness based on culture and age. First, the sample size for the exploration can be increased, and a more heterogeneous sample can be studied to obtain a more diverse understanding of kindness. Second, cognitive and emotional aspects of kindness can be further explored to understand better 
their lesser representation in literature and people's life experiences. Likewise, religiosity, serving as a most representative enabling factor for kindness, can also be studied in detail. Third, future research may also focus on developing a theory on kindness using grounded theory. Finally, a psychometric scale can be developed using the definition of the phenomenon of kindness derived in the present research.

This definition of kindness can be used for developing lessons and stories for the curriculum of schools. This definition can also be used for designing training programs in different organizations and institutes.

\section{ACKNOWLEDGEMENT}

The author is exceptionally grateful to Allah for granting the strength, patience, and capability to undertake and accomplish a task that often seemed excruciatingly difficult. Gratitude is also given to Ms. Arooj Mujeeb and Dr. Rao Nadeem for proficient guidance and comprehensive support; to the author's family and the gatekeepers of the research for all the efforts they have given to conduct the research successfully.

\section{REFERENCES}

Ahmed, Z. S., \& Khan, Z. (2016). Direct and indirect impacts of terrorism on youth in Pakistan. Journal of the Research Society of Pakistan, 53(1), 235-249.

Algoe, S. B., \& Haidt, J. (2009). Witnessing excellence in action: The 'other-praising'emotions of elevation, gratitude, and admiration. The Journal of Positive Psychology, 4(2), 105-127. https:// doi.org/10.1080/17439760802650519
Allport, G. W. (1937). Personality: A psychological interpretation. Holt.

Bader, G., \& Rossi, C. (1998). Focus groups: A stepby-step guide. The Bader Group.

Baldwin, C. P., \& Baldwin, A. L. (1970). Children's judgments of kindness. Child Development, 41(1), 29-47. https://doi.org/10.2307/1127387

Baskerville, K., Johnson, K., Monk-Turner, E., Slone, Q., Standley, H., Stansbury, S., Williams, M., \& Young, J. (2000). Reactions to random acts of kindness. The Social Science Journal, 37, 293-298. https://doi.org/10.1016/S03623319(00)00062-8

Binfet, J. T., \& Gaertner, A. (2015). Children's conceptualizations of kindness at school. Canadian Children, 40(3), 27-40. https:// doi.org/10.18357/jcs.v40i3.15167

Braun, V., \& Clarke, V. (2006). Using thematic analysis in psychology. Qualitative Research in Psychology, 3(2), 77-101. https://doi. org/10.1191/1478088706qp063oa

Bryan, W. V. (2015). The professional helper: The fundamentals of being a helping professional. Charles C Thomas Publisher.

Canter, D., Youngs, D., \& Yaneva, M. (2017). Towards a measure of kindness: An exploration of a neglected interpersonal trait. Personality and Individual Differences, 106, 15-20. https://doi. org/10.1016/j.paid.2016.10.019

Cialdini, R. B., Brown, S. L., Lewis, B. P., Luce, C., \& Neuberg, S. L. (1997). Reinterpreting the empathy-altruism relationship: When one into one equals oneness. Journal of Personality and Social Psychology, 73(3), 481. https://doi. org/10.1037/0022-3514.73.3.481

Cleary, M., \& Horsfall, J. (2016). Kindness and its relevance to everyday life: Some considerations for mental health nurses. Issues in Mental Health Nursing, 37(3), 206-208. https://doi.org/10.3109 /01612840.2016.1140546 
Comunian, A. L. (1998). The kindness scale. Psychological Reports, 83(3), 1351-1361. https://doi.org/10.2466/pr0.1998.83.3f.1351

Crosnoe, R., \& Johnson, M. K. (2011). Research on adolescence in the twenty-first century. Annual Review of Sociology, 37, 439-460. https://doi. org/10.1146/annurev-soc-081309-150008

Davey, A., \& Eggebeen, D. J. (1998). Patterns of intergenerational exchange and mental health. The Journals of Gerontology Series B: Psychological Sciences and Social Sciences, 53(2), 86-95. https://doi.org/10.1093/ geronb/53B.2.P86

Davidsen, A. S. (2013). Phenomenological approaches in psychology and health sciences. Qualitative Research in Psychology, 10(3), 318-339. https:// doi.org/10.1080/14780887.2011.608466

DiSalvo, D. (2009). Forget survival of the fittest: It is kindness that counts. Scientific American. https://www.scientificamerican.com/article/ forget-survival-of-the-fittest/

Exline, J. J., Lisan, A. M., \& Lisan, E. R. (2012). Reflecting on acts of kindness toward the self: Emotions, generosity, and the role of social norms. The Journal of Positive Psychology, 7(1), 45-56. https://doi.org/10.1080/17439760.2011 .626790

Flood R. L., \& Carson E. R. (1993). Dealing with complexity: An introduction to the theory and application of systems science (2nd ed.). Plenum Press.

Frank, D. (2010, May 5). Can babies tell right from wrong? The New York Times. https://www. nytimes.com/video/magazine/1247467772000/ can-babies-tell-right-from-wrong.html

Goodwin, G. L. (2011, May 9). Kindness: The core of 12 religions. Inspire Me Today. https:// inspiremetoday.com/blog/kindness-the-coreof-12-religions/
Haidt, J. (2003). The moral emotions. Handbook of effective sciences, 11, 852-870. Oxford University Press.

Index Mundi. (2018). Pakistan Demographics Profile 2018. Index Mundi. https://www.indexmundi. com/pakistan/demographics_profile.html

Jacob, S. A., \& Ferguson, S. P. (2012). Writing interview protocols and conducting interviews: Tips for students new to the field of qualitative research. The Qualitative Report, 17(42), 1-10. https://doi.org/10.46743/2160-3715/2012.1718

Kohn, A. (1990). Effects of rewards on prosocial behavior. Cooperative Learning, 10(3), 23.

Kvale, S. (1989). To validate is to question. In S. Kvale (Ed.), Issues of validity in qualitative research (pp. 73-92). Studentlitteratur.

Leahy, R. L. (1979). Development of conceptions of prosocial behavior: Information affecting rewards given for altruism and kindness. Developmental Psychology, 15(1), 34. https:// doi.org/10.1037/0012-1649.15.1.34

Lewis, J., \& Ritchie, J. (Eds.). (2003). Qualitative research practice: A guide for social science students and researchers. Sage Publications.

Lyubomirsky, S., Sheldon, K. M., \& Schkade, D. (2005). Pursuing happiness: The architecture of sustainable change. Review of General Psychology, 9(2), 111-131. https://doi. org/10.1037/1089-2680.9.2.111

McGarry, L. J. (1986). Kindness and human nature: thoughts on the high cost of negativeness. Villanova University Press.

Mischel, W., \& Shoda, Y. (1995). A cognitive-affective system theory of personality: reconceptualizing situations, dispositions, dynamics, and invariance in personality structure. Psychological Review, 102(2), 246. https://doi.org/10.1037/0033295X.102.2.246 
Neff, K. D. (2003). The development and validation of a scale to measure self-compassion. Self and Identity, 2(3), 223-250. https://doi. org/10.1080/15298860309027

Otake, K., Shimai, S., Tanaka-Matsumi, J., Otsui, K., \& Fredrickson, B. I. (2006). Happy people become happier through kindness: A counting kindnesses intervention. Journal of Happiness Studies, 7(3), 361-375. http://doi.org/10.1007/ s10902-005-3650-Z

Pagel, M. (2012). Wired for culture: The natural history of human cooperation. Penguin UK.

Peterson, C., \& Seligman, M. (2004). Character strengths and virtues: A handbook and classification (Vol. 1). Oxford University Press.

Phillips, A., \& Taylor, B. (2009). On kindness. Hamish Hamilton Press.

Pollock, L. A. (2011). The practice of kindness in early modern elite society. Past and Present, 211(1), 121-158. https://doi.org/10.1093/pastj/gtq056
Rich, G. J. (2003). The positive psychology of youth and adolescence. Journal of Youth and Adolescence, 32(1), 1-3. https://doi. org/10.1023/A:1021017421413

Rowland, L. (2018). Kindness: Society's golden chain. The Psychologist, 31, 30-34.

Rutherford, E., \& Mussen, P. (1968). Generosity in nursery school boys. Child Development, 755765. https://doi.org/10.2307/1126981

Schnall, S., \& Roper, J. (2012). Elevation puts moral values into action. Social Psychological and Personality Science, 3(3), 373-378. https://doi. org/10.1177/1948550611423595

Stewart, D., \& Shamdasani, P. (1990). Focus groups: Theory and practice. Sage Publications.

Strenta, A., \& Dejong, W. (1981). The effect of a prosocial label on helping behavior. Social Psychology Quarterly, 44, 142-147. https:/doi. org/10.2307/3033711. 
